\title{
Perinatal air pollution exposure and development of asthma from birth to age 10 years
}

\author{
Hind Sbihi, Lillian Tamburic, Mieke Koehoorn and Michael Brauer
}

Affiliation: School of Population and Public Health, University of British Columbia, Vancouver, BC, Canada.

Correspondence: Hind Sbihi, 2206 East Mall, University of British Columbia, Vancouver, BC V6T 1Z3, Canada. E-mail: hind.sbihidubc.ca

ABSTRACT Within-city variation in air pollution has been associated with childhood asthma development, but findings have been inconsistent. We examined whether perinatal air pollution exposure affected asthma onset during "pre-school and "school age" periods in a population-based birth cohort.

65254 children born between 1999 and 2002 in the greater Vancouver metropolitan region were followed until age 10 years using linked administrative health databases. Asthma cases were sex- and age-matched to five randomly chosen controls. Associations between exposure to air pollutants estimated with different methods (interpolation (inverse-distance weighted (IDW)), land use regression, proximity) and incident asthma during the pre-school ( $0-5$ years) and school age (6-10 years) periods were estimated with conditional logistic regression.

6948 and 1711 cases were identified during the pre-school and school age periods, respectively. Following adjustment for birthweight, gestational period, household income, parity, breastfeeding at discharge, maternal age and education, asthma risk during the pre-school years was increased by traffic pollution (adjusted odds ratio using IDW method per interquartile increase (95\% CI): nitric oxide 1.06 (1.01-1.11), nitrogen dioxide 1.09 (1.04-1.13) and carbon monoxide 1.05 (1.01-1.1)). Enhanced impacts were observed amongst low-term-birthweight cases. Associations were independent of surrounding residential greenness.

Within-city air pollution variation was associated with new asthma onset during the pre-school years.

@ERSpublications

Air pollution increases the odds of incident asthma from 0 to 5 years, especially in low-termbirthweight children http://ow.ly/WNEln

This article has supplementary material available from erj.ersjournals.com

Received: May 122015 | Accepted after revision: Dec 062015 | First published online: Feb 092016

Support statement: The Border Air Quality Study was supported in part by Health Canada via an agreement with the British Columbia Centre for Disease Control. Additional support was provided by the Centre for Health and Environment Research at the University of British Columbia, funded by the Michael Smith Foundation for Health Research. H. Sbihi was funded by a Canadian Institutes of Health Research Banting and Best doctoral award. All inferences, opinions and conclusions drawn in this research article are those of the authors, and do not reflect the opinions or policies of the Data Steward(s). Funding information for this article has been deposited with FundRef.

Conflict of interest: Disclosures can be found alongside the online version of this article at erj.ersjournals.com

Copyright OERS 2016 


\section{Introduction}

Asthma is the most common paediatric respiratory disease, and presents a heavy and costly burden [1]. Both environmental and genetic factors play a role in asthma development [2]. Among environmental factors, air pollution has attracted interest because of its link to asthma severity, its ubiquitous nature and the possibility of preventive strategies via exposure reduction [3]. One built environment feature that may reduce air pollution exposure is the presence of green spaces. While the evidence linking childhood asthma with green spaces is scarce and inconsistent [4-7], they may also influence asthma 1) by providing space for increased physical activity, 2) by increasing exposure to microbial diversity and/or pollen, and 3) through directly reducing stress [8].

Qualitative reviews have suggested causal associations [9, 10] between traffic-related air pollution specifically with incident childhood asthma, although recent analyses of the epidemiological evidence indicate divergent results.. Examining within-community variation in air pollution [11] or that from traffic sources [12], meta-analyses reported associations with childhood asthma. However, no evidence of an association was found among children followed up until age 10 years in the ESCAPE (European Study of Cohorts for Air Pollution Effects) analysis of multiple birth cohorts using a common exposure protocol [13]. Possible explanations for these inconsistent findings could be heterogeneity in the impacts of air pollution on different asthma phenotypes [14] at different stages of childhood development or modification by other risk factors. Here, we utilise a 10-year follow-up of over 65000 children to build upon the previous literature and previous work in a subset of this cohort [15] to examine whether air pollution differentially impacted asthma risk during two age periods ("pre-school" and "school age"). We further evaluated whether associations were modified by socioeconomic status, sex, parity, birth outcomes and spatially covarying green space.

\section{Methods}

\section{Cohort description}

A birth cohort was identified using British Columbia (BC) administrative data (Ministry of Health [16, 17], Vital Statistics Agency [18, 19], Perinatal Services BC [20]), through Population Data BC [21] which provides data linkage, development and access to the health services database. This cohort comprised all 1999-2002 live births to mothers who were registered with the provincial universal health insurance programme and who resided for their complete pregnancy in the greater Vancouver metropolitan region [22]. The study protocol was approved by the University of British Columbia Research Ethics Board (H04-80161).

Children were followed for 10 years provided they continued to reside in the province according to $\mathrm{BC}$ Ministry of Health registry data [21]. Members were lost to follow-up if they moved outside the study region or had a gap of $>6$ months in residency. From the 73387 births to mothers with verified residential history in the study area, children were excluded if they died during follow-up ( $n=101)$, were a multiple birth ( $n=988)$ or had missing covariate information ( $n=4103)$, leaving 68195 singletons.

\section{Incident asthma case definition}

Asthma diagnoses for 1999-2009 were identified from physician billing and hospital discharge records [16, 17] (International Classification of Diseases revision 9: 493; revision 10: J45), obtained from the BC Ministry of Health. Using a validated case definition of asthma [23], children with a minimum of two primary-care physician diagnoses or one hospital admission in a rolling 12-month period were identified as asthma cases. A nested case-control design was adopted for analytic efficiency.

\section{Exposure assessment}

Exposure variables were assigned throughout pregnancy for cases and controls, based on residential postal codes recorded at each contact with the healthcare system. A time-weighted average exposure incorporating residential mobility during pregnancy was calculated by the time spent at each postal code and successfully assigned to 65254 study subjects with complete covariate information.

Exposure to air pollution for each cohort member was assigned at their residential six-digit postal code(s), which corresponds to one block-face in urban areas (typically 100-150 m), by three different approaches [22]: land use regression (LUR) models, interpolation of regulatory monitoring data (BC Ministry of Environment and Metro Vancouver) and proximity measures.

LUR models provided high spatial resolution (30 m precision) estimates of exposures to traffic-related air pollutants, including black carbon (BC), fine particulate matter $\left(<2.5 \mu \mathrm{m}, \mathrm{PM}_{2.5}\right)$, nitrogen dioxide $\left(\mathrm{NO}_{2}\right)$ and nitric oxide (NO) $[22,24]$. Since the temporal stability of LUR surfaces showed reasonable backward predictions [25], each LUR model, developed after the cohort inception period, was temporally adjusted based on daily air monitoring measurements to estimate monthly average concentrations which were assigned to individual subjects' residential postal codes during pregnancy. 
Measurements of $\mathrm{NO}_{2}, \mathrm{NO}, \mathrm{BC}, \mathrm{PM}_{10}$, carbon monoxide $(\mathrm{CO})$ and sulfur dioxide $\left(\mathrm{SO}_{2}\right)$ from regulatory monitoring stations were used to compute the inverse-distance weighted (IDW) averages from the three closest monitors within $50 \mathrm{~km}$, and assigned to participants' residential postal codes [26].

Finally, we determined whether a home postal code was within 50 or $150 \mathrm{~m}$ of a primary highway, within 50 or $150 \mathrm{~m}$ of a major road, or within $150 \mathrm{~m}$ of a primary highway and within $50 \mathrm{~m}$ of a major road for each cohort member using a geographic database (DMTI ArcView street file data set for BC, Canmap Streetfiles version 2006.3; DMTI Spatial, Markham, Ontario, Canada).

\section{Covariates}

Birth date, sex, birthweight and gestational duration for each child were accessed via Vital Statistics data [18]. Parity (used as surrogate for presence of siblings), breastfeeding status at the time of discharge, and maternal age and smoking during pregnancy were obtained from the BC Perinatal Data Registry [20]. Since no individual-level data were available for other socioeconomic factors, we assigned subjects to measures of income and maternal education at the Census Dissemination Areas [27], a resolution which approximates the neighbourhood-level, with target populations of 400-700 persons.

\section{Analytical methods}

Each asthma case was randomly matched to five controls by sex and birth month and year, and analysed with nested conditional logistic regression models including breastfeeding status at the time of discharge, parity, maternal education (area-level quartiles), household income (area-level quintiles), gestational length and birthweight. We examined the risk of incident asthma in relation to air pollution: from birth until the child's sixth birthday ("pre-school") and from age 6 years until the end of follow-up ("school age"). The pre-school group was similar to an initial analysis of a subsample of this cohort [15], while the school age group provided insight into the effect of perinatal air pollution exposure on asthma incidence later in childhood. As air pollution and surrounding residential greenness covary independently, we also adjusted for this exposure, assigned for the same time window [28], in sensitivity analyses. Greenness was measured using the satellite-derived Normalised Difference Vegetation Index based on 30-m resolution images and characterised for a 100-m buffer around the home residential postal codes. Pollutants were entered into models as continuous variables to calculate odds ratios (ORs) over an interquartile increase (table 2) following an assessment of the functional relationship between asthma incidence and air pollutants based on smoothing splines (gam function, The R Project for Statistical Computing 2.15.0; http://www.r-project.org). As most of the relationships were found to be close to linear for a wide range of the data (online supplementary figure S1), analyses by exposure quartile were also conducted to assess exposure-response relationships.

Potential modifications of the air pollution effects on childhood asthma incidence by low term birthweight $(<2500$ g), prematurity (30-37 and $<30$ weeks), sex, parity, maternal age at birth, neighbourhood-level household income and maternal post-secondary education were examined in sensitivity analyses.

\section{Results}

Age $($ mean $\pm \mathrm{SD})$ at time of first asthma diagnosis was $2.6 \pm 1.4$ years for 6948 children who met the case

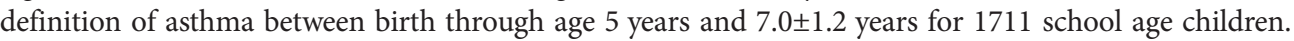

Asthmatic children were more frequently born to a younger mother, with a smaller birthweight and gestation period, from a lower socioeconomic stratum, and less likely to have been breastfed, compared with their matched controls. All risk factors, except for sex, were similar when comparing matched controls to all children who did not meet the case definition, indicating nonbiased selection of control subjects (table 1).

Table 2 summarises the distribution of all spatially derived exposure variables for the cohort strata. Levels of air pollutants in metropolitan Vancouver were relatively low and positively intercorrelated (except for ozone) as reported previously [15]. There were differences in mean exposure levels for LUR compared with IDW metrics, in particular for NO (23 versus $31 \mu \mathrm{g} \cdot \mathrm{m}^{-3}$ for IDW and LUR, respectively), reflecting the enhanced spatial precision of LUR models. Estimated exposures were significantly different between cases and matched controls for IDW-derived $\mathrm{NO}_{2}$ and ozone.

For children with a diagnosis of asthma established in the pre-school years, all interpolation-based exposures except for ozone were positively associated with an increased risk in adjusted models. In addition, proximity to highways and major roads significantly increased the risk of new asthma onset by $25 \%$ and $5 \%$, respectively (table 3 ). The associations with ozone were negatively correlated with asthma incidence due to the negative correlation of ozone with traffic-related air pollutants. These results were consistent with exposures categorised in quartiles (figure 1a).

For both continuous and categorical exposures, all adjusted analyses were robust to the inclusion of additional risk factors (breastfeeding status at discharge, parity, maternal education level and age, income, 
birthweight, and gestational length) with ORs showing similar direction and magnitude of effects as crude analyses. Supplementary analyses (results not shown) using nonparametric regression (locally weighted scatterplot smoothing) confirmed linearity between predicted probabilities for incident asthma throughout the distribution of air pollutant concentrations.

Children for whom incident asthma was only evident from age 6 years onwards showed no consistently elevated risk in relation to air pollutant exposures (table 3). Only exposure to $\mathrm{PM}_{10}$ exhibited some consistency between the two time periods (figure 1), while ozone exposure was associated with an increased risk of developing asthma after 6 years of age (adjusted OR (95\% CI) 1.18 (1.07-1.31)). As most new asthma onset cases were captured during the pre-school period, more investigation is needed to confirm the observed associations during the school age period.

\section{Effect modification}

Stratified regression analyses were conducted only for the pre-school period since this accounted for $70 \%$ of all identified cases and stratified models for the school age period did not converge.

Among children who met the case definition during the pre-school period, 535 (7.7\% of all incident asthma cases) were born at 30-37 weeks of gestation and only $83(1.2 \%)$ at $<30$ weeks. Gestational duration was grouped into a single pre-term category ( $<37$ weeks) to ensure model convergence.

Evidence of effect modification by term birthweight but not gestational duration was demonstrated (figure 2). All the increased risks for children with birthweight $<2500 \mathrm{~g}(\mathrm{n}=442)$, for IDW-derived pollutant exposures, were near double those in children with birthweight $\geqslant 2500 \mathrm{~g}$. Low-term-birthweight children also showed increased risk for LUR exposure estimates.

Stratified regressions by sex revealed that girls were consistently at increased odds of new asthma compared with boys for the same air pollutants identified in the main analysis (online supplementary figure S2). Stratification by parity showed similar but less pronounced results: all exposures with an effect on odds of

TABLE 1 Characteristics of children in the Border Air Quality Study [22] born between 1999 and 2002 meeting the asthma case definition, their age- and sex-matched controls, and nonasthmatic children by time window

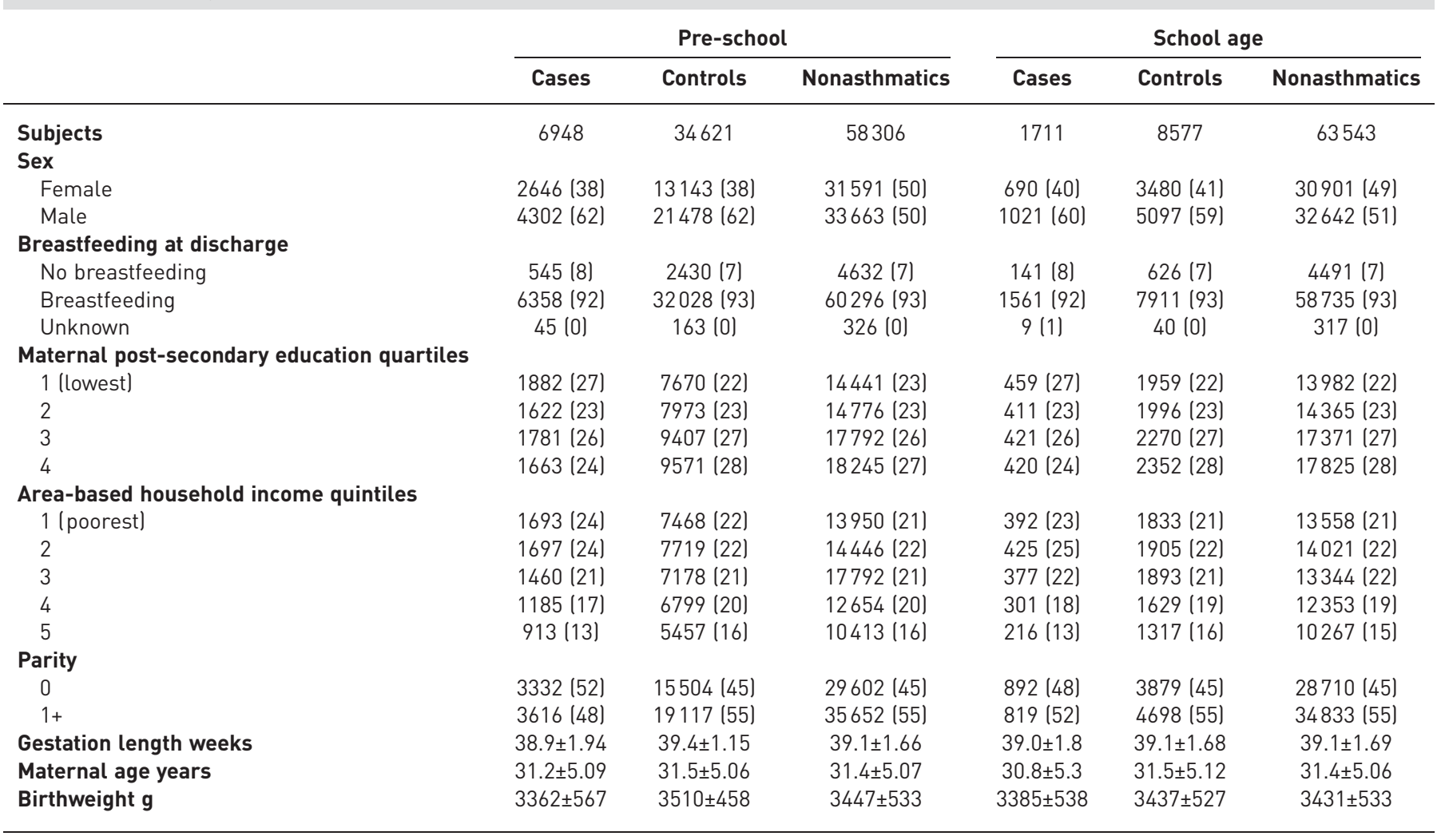

Data are presented as $n, \mathrm{n}(\%)$ or mean \pm SD. 
TABLE 2 Exposure levels among cases and controls for carbon monoxide (CO), nitrogen dioxide $\left(\mathrm{NO}_{2}\right)$, nitrogen monoxide $(\mathrm{NO})$, ozone $\left(\mathrm{O}_{3}\right)$, sulfur dioxide $\left(\mathrm{SO}_{2}\right)$, particulate matter $\left(\mathrm{PM}_{10}\right.$, $\mathrm{PM}_{2.5}$ ) and black carbon (BC) derived using inverse-distance weighted (IDW) and/or land use regression (LUR) models

\begin{tabular}{|c|c|c|}
\hline Pollutant_metric & Pre-school & School age \\
\hline \multicolumn{3}{|l|}{ CO_IDW $\mu \mathrm{g} \cdot \mathrm{m}^{-3}$} \\
\hline Cases & $628.7 \pm 119.6(165.0)$ & $628.2 \pm 120.6(160.4)$ \\
\hline Controls & $626.7 \pm 119.7(163.9)$ & $636.7 \pm 121.9(165.7)$ \\
\hline \multicolumn{3}{|l|}{$\mathrm{NO}_{2} I^{\prime D W} \mu \mathrm{g} \cdot \mathrm{m}^{-3}$} \\
\hline Cases & $33.7 \pm 6.8(9.7)$ & $33.4 \pm 6.8(9.4)$ \\
\hline Controls & $33.3 \pm 7.0(10.0)$ & $33.7 \pm 7.0(10.1)$ \\
\hline \multicolumn{3}{|l|}{ NO_IDW $\mu \mathrm{g} \cdot \mathrm{m}^{-3}$} \\
\hline Cases & $23.0 \pm 10.9(15.6)$ & $22.5 \pm 11.0(15.1)$ \\
\hline Controls & $22.7 \pm 10.9(15.4)$ & $23.0 \pm 11.1(16.0)$ \\
\hline \multicolumn{3}{|l|}{$0_{3} I_{I D W^{\#}} \mu \mathrm{g} \cdot \mathrm{m}^{-3}$} \\
\hline Cases & $27.7 \pm 5.8(8.6)$ & $27.9 \pm 6.0(8.7)$ \\
\hline Controls & $27.9 \pm 5.8(8.5)$ & $28.3 \pm 5.9(8.6)$ \\
\hline \multicolumn{3}{|l|}{$\mathrm{SO}_{2}$ IDW $\mu \mathrm{g} \cdot \mathrm{m}^{-3}$} \\
\hline Cases & $5.67 \pm 2.4(3.2)$ & $5.5 \pm 2.4(2.8)$ \\
\hline Controls & $5.63 \pm 2.4(3.1)$ & $5.7 \pm 2.5(3.3)$ \\
\hline \multicolumn{3}{|l|}{$\mathrm{PM}_{10 \_}$IDW $\mu \mathrm{g} \cdot \mathrm{m}^{-3}$} \\
\hline Cases & $12.5 \pm 1.0(1.3)$ & $12.5 \pm 1.1(1.4)$ \\
\hline Controls & $12.5 \pm 1.0(1.3)$ & $12.5 \pm 1.1(1.3)$ \\
\hline \multicolumn{3}{|l|}{$\mathrm{PM}_{2.5}$ LUR $\mu \mathrm{g} \cdot \mathrm{m}^{-3}$} \\
\hline Cases & $4.09 \pm 1.6(1.4)$ & $4.1 \pm 1.6(1.4)$ \\
\hline Controls & $4.06 \pm 1.7(1.5)$ & $4.0 \pm 1.7(1.5)$ \\
\hline \multicolumn{3}{|l|}{$\mathrm{NO}_{2}$ LUR $\mu \mathrm{g} \cdot \mathrm{m}^{-3}$} \\
\hline Cases & $33.6 \pm 8.8$ (9.35) & $33.2 \pm 8.6(9.1)$ \\
\hline Controls & $33.6 \pm 9.1(9.50)$ & $33.5 \pm 8.9(9.5)$ \\
\hline \multicolumn{3}{|l|}{ NO_LUR $\mu \mathrm{g} \cdot \mathrm{m}^{-3}$} \\
\hline Cases & $31.3 \pm 13.4(14.5)$ & $31.4 \pm 13.2(13.7)$ \\
\hline Controls & $31.3 \pm 13.8(14.6)$ & $31.4 \pm 13.6(14.2)$ \\
\hline \multicolumn{3}{|l|}{ BC_LUR $10^{-5} \cdot \mathrm{m}^{-1}$} \\
\hline Cases & $1.6 \pm 1.2(1.2)$ & $1.6 \pm 1.2(1.1)$ \\
\hline Controls & $1.6 \pm 1.2(1.1)$ & $1.6 \pm 1.2(1.1)$ \\
\hline
\end{tabular}

Data are presented as mean \pm SD (interquartile range). ${ }^{\#}$ : significant paired t-test comparison $(p<0.05)$.

asthma in the main analysis, except $\mathrm{PM}_{10}$, showed a heightened impact for children without siblings (online supplementary figure S2).

Children born in neighbourhoods of lower socioeconomic status (based on neighbourhood income and education) demonstrated higher odds of asthma associated with IDW-derived air pollutant exposures (online supplementary figure S3). Stratification by maternal age at birth showed less consistent results: relative to IDW-derived air pollutants, both the oldest and youngest mothers were likely to have children at higher odds of new asthma development, while LUR estimates showed some increasing trend with age. Formal testing confirmed statistically significant interactions terms for birthweight, sex, parity and socioeconomic status measured by area-level household income for pollutants related to vehicular emissions ( $\mathrm{NO}, \mathrm{NO}_{2}$ and $\left.\mathrm{CO}\right)$.

Given that levels of surrounding greenness in the study area were modestly correlated with the examined air pollutants, joint effects models showed independent and stable effects of air pollution on asthma incidence, except for $\mathrm{PM}_{10}$ (online supplementary tables S1 and S3).

\section{Discussion}

In one of the largest population-based birth cohort studies to examine within-community air pollution contrasts, we found a $25 \%$ increased odds of new asthma onset for children of mothers living near highways during pregnancy, and 5-10\% increases for interquartile range increases in $\mathrm{NO}_{x}$ and $\mathrm{CO}$ derived using IDW. Similar to an earlier analysis of a subset of this cohort [15], we also observed positive associations with $\mathrm{PM}_{10}$ and $\mathrm{SO}_{2}$ exposure [15]. Exposures to air pollution generally did not affect asthma onset when the child was older than age 6 years. 
TABLE 3 Crude and adjusted ${ }^{\#}$ odds ratio (OR) for new asthma onset relative to an interquartile range (IQR) increase in air pollutants derived using inverse-distance weighted (IDW) and/or land use regression (LUR) models, and road proximity

\begin{tabular}{|c|c|c|c|c|c|c|}
\hline & \multicolumn{3}{|c|}{ Pre-school } & \multicolumn{3}{|c|}{ School age } \\
\hline & IQR & $\begin{array}{l}\text { Crude OR } \\
(95 \% \mathrm{CI})\end{array}$ & $\begin{array}{l}\text { Adjusted OR } \\
\text { (95\% CI) }\end{array}$ & IQR & $\begin{array}{l}\text { Crude OR } \\
(95 \% \mathrm{CI})\end{array}$ & $\begin{array}{c}\text { Adjusted OR } \\
(95 \% \mathrm{CI})\end{array}$ \\
\hline NO_IDW $\mu \mathrm{g} \cdot \mathrm{m}^{-3}$ & 15.5 & $\begin{array}{c}1.04 \\
(1.00-1.09)^{9}\end{array}$ & $\begin{array}{c}1.06 \\
(1.01-1.11)^{\pi}\end{array}$ & 15.5 & $\begin{array}{c}0.92 \\
(0.85-1.00)\end{array}$ & $\begin{array}{c}0.93 \\
(0.85-1.02)\end{array}$ \\
\hline NO_LUR $\mu \mathrm{g} \cdot \mathrm{m}^{-3}$ & 14.4 & $\begin{array}{c}1.01 \\
(0.98-1.04)\end{array}$ & $\begin{array}{c}1.00 \\
(0.97-1.03)\end{array}$ & 14.4 & $\begin{array}{c}1.01 \\
(0.95-1.07)\end{array}$ & $\begin{array}{c}1.00 \\
(0.94-1.06)\end{array}$ \\
\hline $\mathrm{NO}_{2} \_\mathrm{LUR} \mu \mathrm{g} \cdot \mathrm{m}^{-3}$ & 9.5 & $\begin{array}{c}1.01 \\
(0.98-1.03)\end{array}$ & $\begin{array}{c}0.99 \\
(0.96-1.02)\end{array}$ & 9.3 & $\begin{array}{c}0.97 \\
(0.92-1.02)\end{array}$ & $\begin{array}{c}0.95 \\
(0.90-1.01)\end{array}$ \\
\hline CO_IDW $\mu \mathrm{g} \cdot \mathrm{m}^{-3}$ & 163.9 & $\begin{array}{c}1.03 \\
(0.99-1.07)\end{array}$ & $\begin{array}{c}1.05 \\
(1.01-1.10)^{9}\end{array}$ & 164.6 & $\begin{array}{c}0.89 \\
(0.83-0.97)\end{array}$ & $\begin{array}{c}0.90 \\
(0.83-0.98)\end{array}$ \\
\hline $\mathrm{O}_{3} \_\mathrm{IDW} \mu \mathrm{g} \cdot \mathrm{m}^{-3}$ & 8.5 & $\begin{array}{c}0.92 \\
(0.88-0.97)^{\pi}\end{array}$ & $\begin{array}{c}0.92 \\
(0.87-0.97)^{\pi}\end{array}$ & 8.5 & $\begin{array}{c}1.17 \\
(1.07-1.29)^{\pi}\end{array}$ & $\begin{array}{c}1.18 \\
(1.07-1.31)^{\pi}\end{array}$ \\
\hline BC_LUR $10^{-5} \cdot \mathrm{m}^{-1}$ & 1.13 & $\begin{array}{c}1.02 \\
(1.00-1.05)^{\pi}\end{array}$ & $\begin{array}{c}1.01 \\
(0.99-1.04)\end{array}$ & 1.13 & $\begin{array}{c}0.89 \\
(0.83-0.95)\end{array}$ & $\begin{array}{c}0.99 \\
(0.95-1.05)\end{array}$ \\
\hline $\mathrm{SO}_{2} \mathrm{IDW} \mu \mathrm{g} \cdot \mathrm{m}^{-3}$ & 3.1 & $\begin{array}{c}1.03 \\
(0.99-1.07)\end{array}$ & $\begin{array}{c}1.05 \\
(1.01-1.09)^{\pi}\end{array}$ & 3.1 & $\begin{array}{c}1.01 \\
(0.96-1.06)\end{array}$ & $\begin{array}{c}0.89 \\
(0.83-0.96)\end{array}$ \\
\hline \multicolumn{7}{|l|}{ Road proximity } \\
\hline Within $50 \mathrm{~m}$ of highway yes/no & & $\begin{array}{c}1.28 \\
(1.07-1.53)^{11}\end{array}$ & $\begin{array}{c}1.25 \\
(1.04-1.49)^{\pi}\end{array}$ & & $\begin{array}{c}1.06 \\
(0.96-1.17)\end{array}$ & $\begin{array}{c}0.81 \\
(0.55-1.19)\end{array}$ \\
\hline Within $150 \mathrm{~m}$ of major road yes/no & & $\begin{array}{c}1.04 \\
(0.98-1.1)\end{array}$ & $\begin{array}{c}1.03 \\
(0.98-1.09)\end{array}$ & & $\begin{array}{c}1.05 \\
(0.94-1.18)\end{array}$ & $\begin{array}{c}1.04 \\
(0.92-1.16)\end{array}$ \\
\hline Within $150 \mathrm{~m}$ of highway or $50 \mathrm{~m}$ of major road yes/no & & $\begin{array}{c}1.06 \\
(0.96-1.17)\end{array}$ & $\begin{array}{c}1.00 \\
(0.94-1.08)\end{array}$ & & $\begin{array}{c}1.08 \\
(0.94-1.24)\end{array}$ & $\begin{array}{c}1.06 \\
(0.92-1.21)\end{array}$ \\
\hline
\end{tabular}

$\mathrm{NO}$ : nitrogen monoxide; $\mathrm{NO}_{2}$ : nitrogen dioxide; $\mathrm{CO}$; carbon monoxide; $\mathrm{O}_{3}$ : ozone; $\mathrm{PM}$ : particulate matter; $\mathrm{BC}$ : black carbon; $\mathrm{SO}_{2}$ : sulfur dioxide. \#: models were adjusted for breastfeeding status at the time of discharge, parity, maternal education (in area-level quartiles), household income (in area-level quintiles), gestational length and birthweight; ${ }^{\text {I: }}$ statistically significant associations ( $\left.p<0.05\right)$.

The most recent birth cohort studies with similar follow-up durations show mixed results with regard to the role of air pollution on asthma incidence. A British birth cohort reported no association between $\mathrm{NO}_{2}$ nor $\mathrm{PM}_{10}$ and asthma in children who were followed up until 11 years of age [29]. The Swedish BAMSE (Children, Allergy, Milieu, Stockholm, Epidemiological Survey) cohort reported a positive association between air pollution and asthma only among older children [30], although the number of identified cases in BAMSE at increasing ages did not follow the decreasing pattern found in our study. However, similar to our analysis, the Dutch PIAMA (Prevention and Incidence of Asthma and Mite Allergy) cohort [31] reported positive associations between $\mathrm{NO}_{2}$ and asthma at age 2 and 4 years [32, 33] with most incident cases apparent earlier in life. Unlike in our study, however, the increased risk of incident asthma in relation to $\mathrm{NO}_{2}$ and $\mathrm{PM}_{2.5}$ exposure was still evident for incident asthma at older ages (up to age 8 years), possibly due to higher air pollution levels [31].

In both PIAMA and BAMSE, asthma was defined based on questionnaires, unlike this study where medical records were used. Furthermore, as the BAMSE case definition was augmented in later ages by adding the use of medication, differences in asthma case definitions can also explain the difference in results. Our asthma case definition, although verified in other population-based administrative data analyses [34, 35], relied on healthcare system encounters and may have captured wheezing illnesses that have varying trajectories over time [36]. Transient wheezing is common in infants and often resolves in childhood [37]. In a population-based Canadian study, half the children diagnosed with asthma before age 6 years went into remission by age 12 years [38]. While the pre-school analysis may have included children whose symptoms resolved later, weakening the ability to detect associations during school years, misclassification is unlikely as among those children diagnosed prior to age 6 years, $77 \%$ remained 

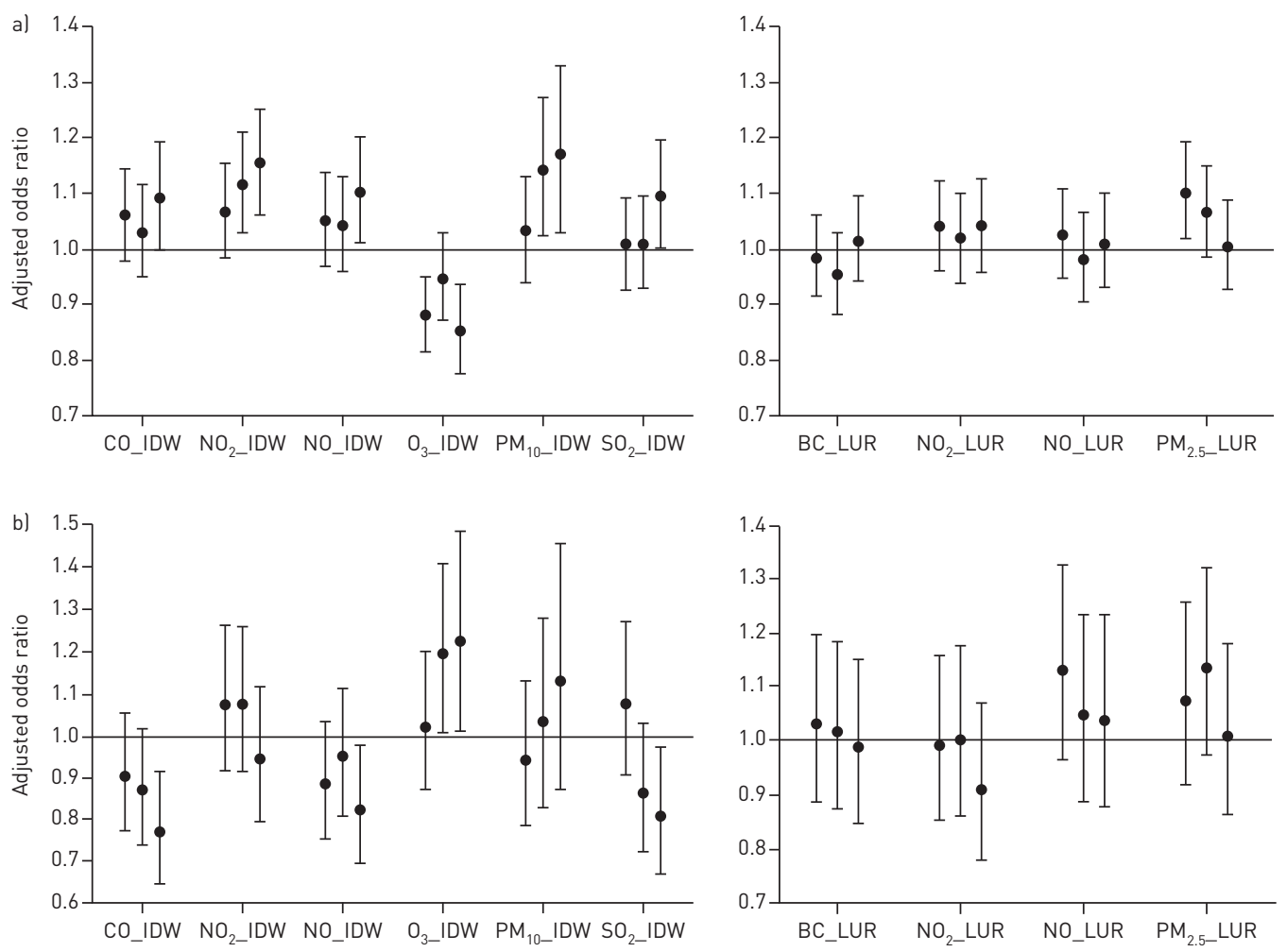

FIGURE 1 Adjusted odds ratio (OR) $(95 \% \mathrm{Cl})$ of incident asthma in children meeting the case definition in the a) pre-school and b) school age groups relative to exposure quartiles of air pollutants: carbon monoxide (CO), nitrogen dioxide $\left(\mathrm{NO}_{2}\right)$, nitrogen monoxide $(\mathrm{NO})$, ozone $\left(\mathrm{O}_{3}\right)$, particulate matter $\left(\mathrm{PM}_{10}, \mathrm{PM}_{2.5}\right)$, sulfur dioxide $\left(\mathrm{SO}_{2}\right)$ and black carbon (BC) derived by interpolation (IDW) and land use regression (LUR). For each metric, the three points plotted represent the $\mathrm{OR}$ by quartile. The first point is the OR for the second quartile, the second point is the $\mathrm{OR}$ for the third quartile and the third point is the OR for the fourth quartile. The reference category is not plotted (first quartile: $\mathrm{OR}=1$ ). See online supplementary table $\mathrm{S} 2$ for exposure levels per quartile.

asthmatic in later childhood (results not shown). A recent position paper on the diagnosis of asthma in pre-schoolers supported the importance of early age diagnoses [39]. Future studies of asthma trajectories using linked health databases can help elucidate asthma phenotypes where incidence is affected by air pollution.

Administrative data are not collected for research purposes and lack individual-level information (e.g. socioeconomic status measures), and therefore may be subject to residual confounding. Similarly, adjustment for parental asthma was not available in the linked health databases and remains an intrinsic limitation of this population-based investigation. However, such linked health records provide unprecedented opportunities to investigate multiple risk factors in a large population. The population-based study design reduces the potential for bias, including that related to genetic factors.

For all air pollutants apart from $\mathrm{PM}_{10}$ and for road proximity metrics, the direction and magnitude of effects did not change when controlling for surrounding greenness. This finding is consistent with our observation of an association in this cohort between increased greenness and reduced asthma incidence that remained even when air pollution exposure was considered [40]. Despite the ability of LUR exposure assessments to provide increased spatial precision, associations were consistently larger for IDW estimates compared with LUR estimates. This result is line with previous investigations in this cohort examining the effect of traffic-related air pollution on birth outcomes [22] and asthma in early life [15], and suggests that LUR may be more relevant for primary pollutants such as NO and black carbon. A previous study evaluated these and several other exposure metrics, and suggested that interpolation and LUR estimates reflect different spatial scales which may be partially independent of each other [26]. Both types of exposure estimates, whether derived using LUR or IDW, showed only modest (although somewhat higher with LUR) correlations, with personal monitoring in a study of pregnant women in Vancouver [41] suggesting that both IDW and LUR capture partially independent components of personal exposure to the traffic-related air pollution mixture. Our findings should also be considered in light of the limitation that 

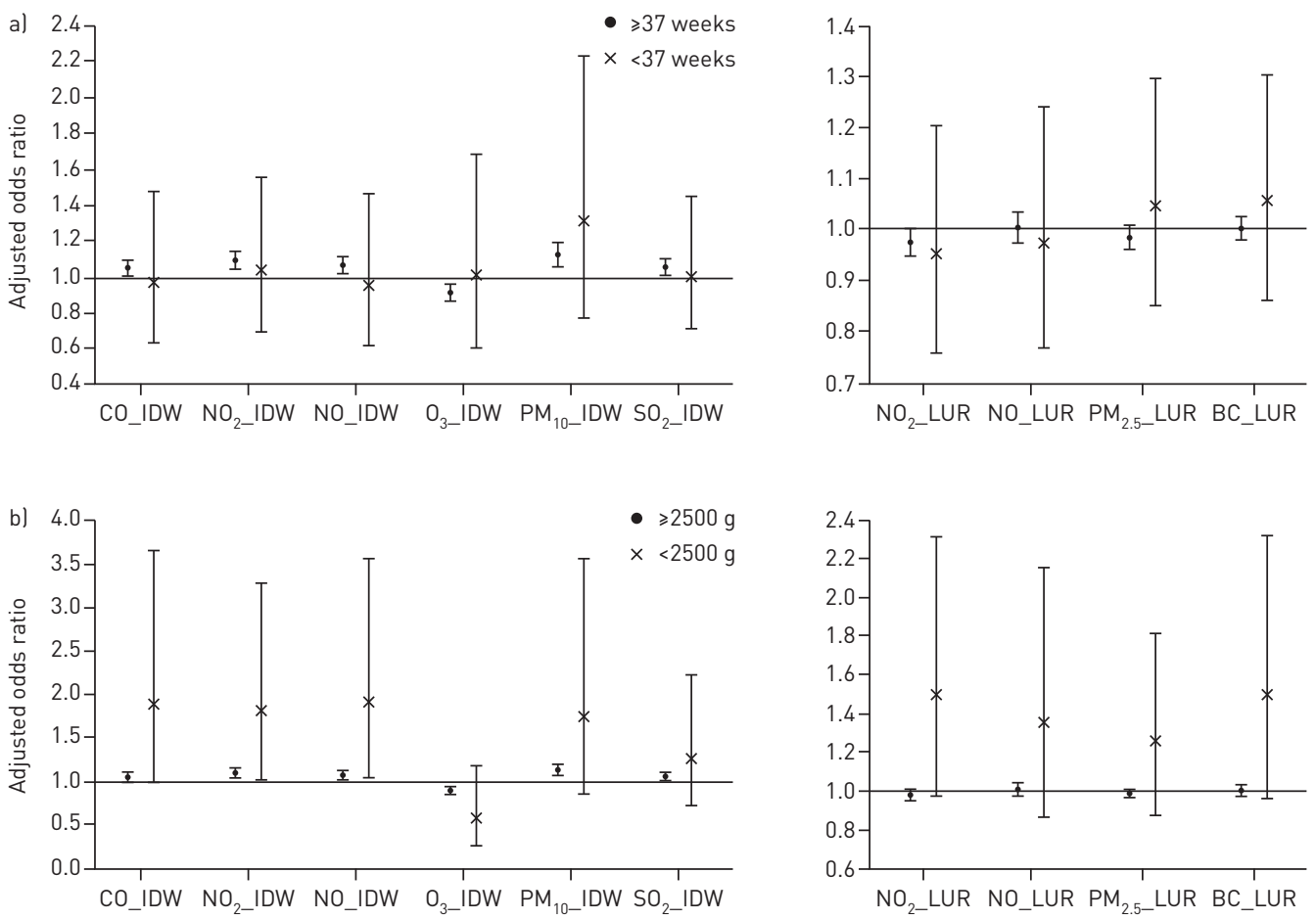

FIGURE 2 Effect modification ladjusted odds ratio (95\% CI)) of air pollution (carbon monoxide (CO), nitrogen dioxide $\left(\mathrm{NO}_{2}\right)$, nitrogen monoxide $(\mathrm{NO})$, ozone $\left(\mathrm{O}_{3}\right)$, particulate matter $\left(\mathrm{PM}_{10}, \mathrm{PM}_{2.5}\right)$, sulfur dioxide $\left(\mathrm{SO}_{2}\right)$ and black carbon (BC)) estimates derived using inverse-distance weighed (IDW) and land use regression (LUR) models on new asthma onset among pre-school children by al gestational length and b) birthweight. All models are adjusted for maternal age at delivery, neighbourhood-level household income, neighbourhood-level maternal education, parity and breastfeeding status at discharge.

exposures in microenvironments other than the home during pregnancy were not considered, leading to potential exposure misclassification. Indeed, in the NeTHERY et al. [41] study of pregnant women in Vancouver, better agreement with personal exposure was shown when work/school addresses were included. However, Gruzieva et al. [30] reported in their analysis where several microenvironments were considered that early life exposures would be less affected by the threat of misclassification when considering home addresses only. In the absence of linked residential histories throughout the follow-up period, no formal comparison of pregnancy and post-natal exposures was conducted. This limitation may be partially offset by a prior investigation of a subset of this cohort which suggested that pre-natal exposures had a slightly larger impact on asthma compared with exposures in the first years of life [15].

Pre-school children weighing $<2500 \mathrm{~g}$ at birth were consistently, across all metrics, at increased risk for new asthma onset in relation to air pollution exposure, supporting the idea of greater susceptibility among low-birthweight subpopulations [42].

Similar to the Children's Health Study results [43], being born to a nulliparous mother increased the risk of asthma incidence. This observation may reflect the importance of the in utero environment, given evidence of reduced proliferative responses in cord blood mononuclear cells with increasing parity [44]. We also confirmed the previously observed effect modification of air pollution's effects on childhood respiratory morbidity by socioeconomic status [45]. Furthermore, children born to older mothers were at higher risk of being impacted by air pollution exposure, a relevant finding as BC has the highest proportion of mothers giving birth over the age of 35 years in Canada [46].

In conclusion, the majority of incident asthma occurred during the pre-school years. During this period, the impact of air pollution on asthma incidence was enhanced among low-term-birthweight children.

\section{References}

1 Ismaila AS, Sayani AP, Marin M, et al. Clinical, economic, and humanistic burden of asthma in Canada: a systematic review. BMC Pulm Med 2013; 13: 70.

2 Subbarao P, Becker A, Brook JR, et al. Epidemiology of asthma: risk factors for development. Expert Rev Clin Immunol 2009; 5: 77-95.

3 Guarnieri M, Balmes JR. Outdoor air pollution and asthma. Lancet 2014; 383: 1581-1592. 
Lovasi GS, Quinn JW, Neckerman KM, et al. Children living in areas with more street trees have lower prevalence of asthma. J Epidemiol Community Health 2008; 62: 647-649.

5 Lovasi GS, O’Neil-Dunne JPM, Lu JWT, et al. Urban tree canopy and asthma, wheeze, rhinitis, and allergic sensitization to tree pollen in a New York city birth cohort. Environ Health Perspect 2013; 121: 494-500.

6 Dadvand P, Villanueva CM, Font-Ribera L, et al. Risks and benefits of green spaces for children: a cross-sectional study of associations with sedentary behavior, obesity, asthma, and allergy. Environ Health Perspect 2014; 122: 1329-1335.

7 Pilat MA, McFarland A, Snelgrove A, et al. The effect of tree cover and vegetation on incidence of childhood asthma in metropolitan statistical areas of Texas. HortTechnology 2012; 22: 631-637.

8 Hartig T, Mitchell R, de Vries S, et al. Nature and health. Annu Rev Public Health 2014; 35: $207-228$.

9 Bråbäck L, Forsberg B. Does traffic exhaust contribute to the development of asthma and allergic sensitization in children: findings from recent cohort studies. Environ Health 2009; 8: 17.

10 Health Effects Institute. Traffic Related Air Pollution: A Critical Review of the Literature on Emissions, Exposure, and Health Effects, 2010. http://pubs.healtheffects.org/view.php?id=334 Date last accessed February 12, 2015.

11 Anderson Hr, Favarato G, Atkinson RW. Long-term exposure to air pollution and the incidence of asthma: meta-analysis of cohort studies. Air Qual Atmos Health 2013; 6: 47-56.

12 Gasana J, Dillikar D, Mendy A, et al. Motor vehicle air pollution and asthma in children: a meta-analysis. Environ Res 2012; 117: 36-45.

13 Mölter A, Simpson A, Berdel D, et al. A multicentre study of air pollution exposure and childhood asthma prevalence: the ESCAPE project. Eur Respir J 2015; 45: 610-624.

14 Gowers AM, Cullinan P, Ayres JG, et al. Does outdoor air pollution induce new cases of asthma? Biological plausibility and evidence; a review. Respirology 2012; 17: 887-898.

15 Clark NA, Demers PA, Karr CJ, et al. Effect of early life exposure to air pollution on development of childhood asthma. Environ Health Perspect 2010; 118: 284-290.

16 British Columbia Ministry of Health. Medical Services Plan (MSP) Payment Information File V2. Population Data BC. Data Extract, BC Ministry of Health, 2009. https://www.popdata.bc.ca/data

17 British Columbia Ministry of Health. Discharge Abstract Database (Hospital Separations) V2. Population Data BC. Data Extract, BC Ministry of Health, 2009. https://www.popdata.bc.ca/data

18 British Columbia Vital Statistics Agency. Vital Statistics Births V2. Population Data BC. Data Extract, BC Vital Statistics Agency, 2009. http://www.popdata.bc.ca/data

19 British Columbia Vital Statistics Agency. Vital Statistics Deaths V2. Population Data BC. Data Extract, BC Vital Statistics Agency, 2009. http://www.popdata.bc.ca/data

20 Perinatal Services BC. BC Perinatal Data Registry. Population Data BC. Data Extract, Perinatal Services BC, 2009. http://www.perinatalservicesbc.ca/health-professionals/data-surveillance/perinatal-data-registry

21 British Columbia Ministry of Health. Population Data BC. https://www.popdata.bc.ca/data

22 Brauer M, Lencar C, Tamburic L, et al. A cohort study of traffic-related air pollution impacts on birth outcomes. Environ Health Perspect 2008; 116: 680-686.

23 Prosser RJ, Carleton BC, Smith MA. Identifying persons with treated asthma using administrative data via latent class modelling. Health Serv Res 2008; 43: 733-754.

24 Henderson SB, Beckerman B, Jerrett M, et al. Application of land use regression to estimate long-term concentrations of traffic-related nitrogen oxides and fine particulate matter. Environ Sci Technol 2007; 41: $2422-2428$.

25 Wang R, Henderson SB, Sbihi H, et al. Temporal stability of land use regression models for traffic-related air pollution. Atmos Environ 2013; 64: 312-319.

26 Marshall JD, Nethery E, Brauer M. Within-urban variability in ambient air pollution: comparison of estimation methods. Atmos Environ 2008; 42: 1359-1369.

27 Statistics Canada. Census of Canada 2001 Archive. Ottawa, Statistics Canada, 2001.

28 Hystad P, Davies HW, Frank L, et al. Residential greenness and birth outcomes: evaluating the influence of spatially correlated built-environment factors. Environ Health Perspect 2014; 122: 1095-1102.

29 Mölter A, Agius R, de Vocht F, et al. Effects of long-term exposure to $\mathrm{PM}_{10}$ and $\mathrm{NO}_{2}$ on asthma and wheeze in a prospective birth cohort. J Epidemiol Community Health 2014; 68: 21-28.

30 Gruzieva O, Bergström A, Hulchiy O, et al. Exposure to air pollution from traffic and childhood asthma until 12 years of age. Epidemiology 2013; 24: 54-61

31 Gehring U, Wijga AH, Brauer M, et al. Traffic-related air pollution and the development of asthma and allergies during the first 8 years of life. Am J Respir Crit Care Med 2010; 181: 596-603.

32 Gehring U, Cyrys J, Sedlmeir G, et al. Traffic-related air pollution and respiratory health during the first 2 yrs of life. Eur Respir J 2002; 19: 690-698.

33 Brauer M, Hoek G, Smit HA, et al. Air pollution and development of asthma, allergy and infections in a birth cohort. Eur Respir J 2007; 29: 879-888.

34 To T, Dell S, Dick PT, et al. Case verification of children with asthma in Ontario. Pediatr Allergy Immunol 2006; 17: 69-76.

35 Kozyrskyj AL, Mustard CA, Becker AB. Identifying children with persistent asthma from health care administrative records. Can Respir J 2004; 11: 141-145.

36 Stein RT, Martinez FD. Asthma phenotypes in childhood: lessons from an epidemiological approach. Paediatr Respir Rev 2004; 5: 155-161.

37 Martinez FD, Wright AL, Taussig LM, et al. Asthma and wheezing in the first six years of life. N Engl J Med 1995; 332: $133-138$

38 To T, Gershon A, Wang C, et al. Persistence and remission in childhood asthma: a population-based asthma birth cohort study. Arch Pediatr Adolesc Med 2007; 161: 1197-1204.

39 Ducharme FM, Dell SD, Radhakrishnan D, et al. Diagnosis and management of asthma in preschoolers: a Canadian Thoracic Society and Canadian Paediatric Society position paper. Can Respir J 2015; 22 : $135-143$.

40 Sbihi H, Tamburic L, Koehoorn M, et al. Greenness and incident childhood asthma: a 10-year follow-up in a population-based birth cohort. Am J Respir Crit Care Med 2015; 192: 1131-1133. 
41 Nethery E, Leckie SE, Teschke K, et al. From measures to models: an evaluation of air pollution exposure assessment for epidemiological studies of pregnant women. Occup Environ Med 2008; 65: 579-586.

42 Strickland MJ, Klein M, Flanders WD, et al. Modification of the effect of ambient air pollution on pediatric asthma emergency visits: susceptible subpopulations. Epidemiology 2014; 25: 843-850.

43 Salam MT, Li Y-F, Langholz B, et al. Early-life environmental risk factors for asthma: findings from the Children's Health Study. Environ Health Perspect 2004; 112: 760-765.

44 Devereux G, Barker RN, Seaton A. Antenatal determinants of neonatal immune responses to allergens. Clin Exp Allergy 2002; 32: 43-50.

45 Gehring U, Pattenden S, Slachtova H, et al. Parental education and children's respiratory and allergic symptoms in the Pollution and the Young (PATY) study. Eur Respir J 2006; 27: 95-107.

46 Canadian Institute for Health Information. In Due Time: Why Maternal Age Matters, 2011. https://secure.cihi.ca/ estore/productFamily.htm?locale=en\&pf=PFC1656 Date last accessed December 8, 2014. 